Article

\title{
Comparison of Two Species of Notopterygium by GC-MS and HPLC
}

\section{Yaping Wang and Linfang Huang *}

Institute of Medicinal Plant Development, Chinese Academy of Medical Sciences \& Peking Union Medical College, Beijing 100193, China; E-Mail: ypwang90@126.com

* Author to whom correspondence should be addressed; E-Mail: 1fhuang@implad.ac.cn;

Tel.: +86-10-5783-3197; Fax: +86-10-6289-9700.

Academic Editor: Marcello Iriti

Received: 19 January 2015 / Accepted: 4 March 2015 / Published: 19 March 2015

\begin{abstract}
Notopterygii Rhizoma et Radix (Qianghuo), including Notopterygium incisum Ting ex H. T. Chang (NI) and Notopterygium franchetii $\mathrm{H}$. de Boiss (NF), is an important traditional Chinese medicine. Of these two plants, NI, is more commonly used and has a much higher price in the marketplace. To compare these two plants, a combination of gas chromatography-mass spectrometry (GC-MS) and high performance liquid chromatography (HPLC) was carried out, thus obtaining an overall characterization for both volatile and none-volatile compounds. Combined with hierarchical cluster analysis (HCA) and principal component analysis, GC-MS was successfully applied to distinguish NF and NI. The chemical constitutes of volatile oil in NI and NF were firstly compared in detail, and $1 R$-alpha-pinene, beta-pinene and 4-isopropyl-1-methyl-1,4-cyclohexadiene had great contribution to the discrimination. Fingerprints of 14 batches of Qinghuo samples were also established based on HPLC, and an obvious difference was found between the two species. The chromatographic fingerprints were further analyzed by similarity analysis and HCA. The present study is the first reported evaluation of two origins of Notopterygii Rhizoma et Radix by GC-MS and HPLC, which will facilitate quality control and its clinical application.
\end{abstract}

Keywords: Notopterygium incisum; Notopterygium franchetii; HPLC; GC-MS; chemometrics 


\section{Introduction}

Notopterygii Rhizoma et Radix (Qianghuo), a well-known traditional Chinese medicine, originates from the dried rhizome and root of Notopterygium incisum Ting ex H. T. Chang (NI) and Notopterygium franchetii H. de Boiss. (NF) according to the Chinese Pharmacopoeia (2010 edition) [1] and is famous for its diaphoretic, antifebrile, antirheumatic and anodyne characteristics in the treatment of rheumatism, headaches and colds [2,3]. Qianghuo, endemic to high altitude regions, is mainly distributed in Tibet, Sichuan, Qinghai and Gansu of China. Its main chemical constituents are coumarins, phenoloids and essential oils [4-8]. Pharmacological studies have indicated that coumarins, such as notopterol, bergapten and isoimperatorin, possess anti-inflammatory, analgesic, anti-cancer and anti-coagulant activities [9-11], and the volatile oils possess antifebrile, anodyne and anti-inflammatory activities [12]. However, the two origins of Qianghuo differ in terms of the cultivation altitude: NI usually grows at altitudes above of $3700 \mathrm{~m}$, while NF grows at about $1600 \mathrm{~m}$ [13]. Due to overexploitation and habitat degeneration in recent years, Qianghuo is becoming endangered. In order to protect wildlife resources and to solve the market demand, quality control of Qianghuo is needed. Previous qualitative and quantitative analysis studies of Qinghuo have mainly focused on thin layer chromatography (TLC) [14], gas chromatography-mass spectrometry (GC-MS) [15], high performance liquid chromatography (HPLC) [16,17] and HPLC coupled with mass spectrometry (HPLC-MS) [18]. However, few studies have done a simultaneous analysis of the volatile and non-volatile components between NF and NI as a comparative study.

In order to qualitatively and quantitatively distinguish NF and NI, the combination of GC-MS and HPLC fingerprinting of multiple components of the two plants was conducted. The dataset obtained from GC-MS and HPLC was processed by principal component analysis (PCA) and hierarchical cluster analysis (HCA) to compare the difference of the two species.

\section{Results and Discussion}

\subsection{Analysis of Volatile Compounds by GC-MS}

Volatile compounds comprise an important part of Qianghuo. For example, D-limonene shows multiple pharmacological effects, including antitussive, antibacterial and the inhibition of tumor [19,20]. The volatile oil compositions of Qianghuo were different [21]. In Figure 1 and Table 1, 39 compounds in NI and NF show differences in chromatography profiling and relative contents. The contents of $1 R$-alpha-pinene, beta-pinene, D-limonene and 1-terpinen-4-ol were relatively higher in NI than in NF samples; whereas another two main components (4-isopropyl-1-methyl-1,4-cyclohexadiene and b-thujene) have a higher content in NF. Nine compounds were only detected in NI: bulnesol, 1-methyl-4-(1- methylethylidene)-cyclohexene, shyobunone, epicedrol, (6R)-1,1,5,9-tetramethylspiro [5.5] undeca-1,8-diene, guaiol, dehydroxy-isocalamendiol, r-eudesmol and 1-methyl-4-(1-methylethyl)cyclohexene. Twelve compounds were only detected in NF: 3,7-dimethyl-1,3,6-octatriene, 2,6-dimethyl-2,4,6-octatriene, pentanoic acid, 2-methylbutyl ester, 2-butenoic acid, 2-methyl-, 3methylbutyl ester, 1-isopropyl-2-methoxy-4-methylbenzene, 3-methyl-2-butenoic acid, alpha-bisabolol, octahydro-4,4,8,8-tetramethyl-4a,7-methano-4aH-naphth[1,8a-b]oxirene, apiol, 9-aristolene, agarospirol and Z-3-decen-1-yl acetate. In HCA and PCA, Cluster I was the NF samples, and Cluster II was the NI 
samples (Figures 2 and 3). This results present that NI and NF could be separated based on volatile oils by GC/MS. The loading plot of PCA (Figure 3) indicated that $1 R$-alpha-pinene, beta-pinene and 4-isopropyl-1-methyl-1,4-cyclohexadiene had a great contribution toward the discrimination of NI and NF.

Table 1. Compounds identified by GC-MS.

\begin{tabular}{|c|c|c|c|c|c|c|}
\hline Peak No. & $t_{R} / \mathbf{m i n}$ & Name & Formula & CAS & Area $/ \%$ in NI & Area $/ \%$ in NF \\
\hline $1 \mathrm{a}$ & 7.612 & $1 R$-alpha-pinene & $\mathrm{C}_{10} \mathrm{H}_{16}$ & $7785-70-8$ & 34.61 & 8.86 \\
\hline $2 \mathrm{a}$ & 9.331 & b-thujene & $\mathrm{C}_{10} \mathrm{H}_{16}$ & $28634-89-1$ & 3.91 & 4.49 \\
\hline $3 a$ & 9.576 & beta-pinene & $\mathrm{C}_{10} \mathrm{H}_{16}$ & $18172-67-3$ & 25.79 & 19.89 \\
\hline $4 a$ & 11.98 & D-limonene & $\mathrm{C}_{10} \mathrm{H}_{16}$ & $5989-27-5$ & 9.59 & 4.28 \\
\hline $5 \mathrm{a}$ & 13.243 & $\begin{array}{l}\text { 4-isopropyl-1-methyl-1,4- } \\
\text { cyclohexadiene }\end{array}$ & $\mathrm{C}_{10} \mathrm{H}_{16}$ & $99-85-4$ & 2.18 & 21.23 \\
\hline $6 a$ & 17.949 & 1-terpinen-4-ol & $\mathrm{C}_{10} \mathrm{H}_{18} \mathrm{O}$ & $20126-76-5$ & 1.63 & 1.02 \\
\hline 7 & 5.187 & ethylbenzene & $\mathrm{C}_{8} \mathrm{H}_{10}$ & $100-41-4$ & 0.15 & 0.19 \\
\hline 8 & 7.237 & 3-thujene & $\mathrm{C}_{10} \mathrm{H}_{16}$ & $2867-5-2$ & 0.49 & 0.22 \\
\hline 9 & 8.283 & camphene & $\mathrm{C}_{10} \mathrm{H}_{16}$ & $79-92-5$ & 0.61 & 0.4 \\
\hline 10 & 10.146 & beta-myrcene & $\mathrm{C}_{10} \mathrm{H}_{16}$ & $123-35-3$ & 0.4 & 0.54 \\
\hline 11 & 10.933 & alpha-phellandrene & $\mathrm{C}_{10} \mathrm{H}_{16}$ & $99-83-2$ & 25.79 & 0.9 \\
\hline 12 & 11.034 & 3-carene & $\mathrm{C}_{10} \mathrm{H}_{16}$ & $13466-78-9$ & 10.56 & 0.48 \\
\hline 13 & 11.409 & 2-carene & $\mathrm{C}_{10} \mathrm{H}_{16}$ & $554-61-0$ & 0.62 & 0.48 \\
\hline 14 & 11.828 & 1-methyl-2-(methylethyl)-benzene & $\mathrm{C}_{10} \mathrm{H}_{14}$ & $527-84-4$ & 0.92 & 11.38 \\
\hline 15 & 12.041 & $\begin{array}{l}\text { 4-methylene-1-(1-methylethyl)- } \\
\text { bicyclo[3.1.0]hexane }\end{array}$ & $\mathrm{C}_{10} \mathrm{H}_{16}$ & $3387-41-5$ & 0.18 & 1.11 \\
\hline 16 & 12.766 & 3,7-dimethyl-1,3,6-octatriene & $\mathrm{C}_{10} \mathrm{H}_{16}$ & $3338-55-4$ & 0 & 4.52 \\
\hline 17 & 14.181 & $\begin{array}{l}\text { 1-methyl-4-(1-methylethyl)- } \\
\text { cyclohexene }\end{array}$ & $\mathrm{C}_{20} \mathrm{H}_{36}$ & $34363-01-4$ & 0.1 & 0 \\
\hline 18 & 14.325 & 2,6-dimethyl-2,4,6-octatriene & $\mathrm{C}_{10} \mathrm{H}_{16}$ & $673-84-7$ & 0 & 0.38 \\
\hline 19 & 14.333 & $\begin{array}{l}\text { 1-methyl-4-(1- methylethylidene)- } \\
\text { cyclohexene }\end{array}$ & $\mathrm{C}_{10} \mathrm{H}_{16}$ & $586-62-9$ & 0.56 & 0 \\
\hline 20 & 15.155 & $\begin{array}{c}\text { pentanoic acid, 2-methylbutyl } \\
\text { ester }\end{array}$ & $\mathrm{C}_{10} \mathrm{H}_{20} \mathrm{O}_{2}$ & $55590-83-5$ & 0 & 0.25 \\
\hline 21 & 18.295 & $\begin{array}{l}\text { 2-butenoic acid, 2-methyl-, } \\
\text { 3-methylbutyl ester }\end{array}$ & $\mathrm{C}_{10} \mathrm{H}_{18} \mathrm{O}_{2}$ & $66917-62-2$ & 0 & 1.21 \\
\hline 22 & 19.478 & $\begin{array}{l}\text { 1-isopropyl-2-methoxy-4- } \\
\text { methylbenzene }\end{array}$ & $\mathrm{C}_{11} \mathrm{H}_{16} \mathrm{O}$ & $1076-56-8$ & 0 & 2.01 \\
\hline 23 & 19.796 & 3-methyl-2-butenoic acid & $\mathrm{C}_{11} \mathrm{H}_{16} \mathrm{O}_{2}$ & - & 0 & 0.93 \\
\hline 24 & 21.241 & $\begin{array}{c}(1 S, 2 R, 4 S) \text {-bicyclo[2.2.1]heptan- } \\
\text { 2-ol,1,7,7-trimethyl-, 2-acetate }\end{array}$ & $\mathrm{C}_{12} \mathrm{H}_{20} \mathrm{O}_{2}$ & $5655-61-8$ & 1.86 & 1.21 \\
\hline 25 & 25.281 & Z-3-decen-1-yl acetate & $\mathrm{C}_{12} \mathrm{H}_{22} \mathrm{O}_{2}$ & $81634-99-3$ & 0 & 2.78 \\
\hline 26 & 29.173 & shyobunone & $\mathrm{C}_{15} \mathrm{H}_{24} \mathrm{O}$ & - & 0.34 & 0 \\
\hline 27 & 29.845 & epicedrol & $\mathrm{C}_{15} \mathrm{H}_{26} \mathrm{O}$ & $19903-73-2$ & 1.07 & 0 \\
\hline 28 & 29.981 & $\begin{array}{c}\text { d-cadinene } \\
\text { octahydro-4,4,8,8-tetramethyl- }\end{array}$ & $\mathrm{C}_{15} \mathrm{H}_{24}$ & $483-76-1$ & 1.13 & 1.46 \\
\hline 29 & 30.214 & $\begin{array}{l}\text { 4a,7-methano-4aH-naphth[1,8a- } \\
\text { b]oxirene }\end{array}$ & $\mathrm{C}_{15} \mathrm{H}_{24} \mathrm{O}$ & $67999-56-8$ & 0 & 0.56 \\
\hline
\end{tabular}


Table 1. Cont.

\begin{tabular}{|c|c|c|c|c|c|c|}
\hline Peak No. & $t_{R} / \min$ & Name & Formula & CAS & Area $/ \%$ in NI & Area $/ \%$ in NF \\
\hline 30 & 30.249 & $\begin{array}{c}(6 R) \text {-1,1,5,9-tetramethylspiro } \\
\text { [5.5] undeca-1,8-diene }\end{array}$ & $\mathrm{C}_{15} \mathrm{H}_{24}$ & $19912-83-5$ & 0.77 & 0 \\
\hline 31 & 31.974 & guaiol & $\mathrm{C}_{15} \mathrm{H}_{26} \mathrm{O}$ & $489-86-1$ & 0.64 & 0 \\
\hline 32 & 32.162 & dehydroxy-isocalamendiol & $\mathrm{C}_{15} \mathrm{H}_{24} \mathrm{O}$ & - & 0.4 & 0 \\
\hline 33 & 32.208 & r-eudesmol & $\mathrm{C}_{15} \mathrm{H}_{26} \mathrm{O}$ & $473-16-5$ & 0.87 & 0 \\
\hline 34 & 32.514 & apiol & $\mathrm{C}_{12} \mathrm{H}_{14} \mathrm{O}_{4}$ & $523-80-8$ & 0 & 0.75 \\
\hline 35 & 32.717 & $\begin{array}{c}1 R, 4 S, 7 S, 11 R-2,2,4,8- \\
\text { tetramethyltricyclo } \\
{[5.3 .1 .0(4,11)] \text { undec-8-ene }}\end{array}$ & $\mathrm{C}_{15} \mathrm{H}_{24}$ & - & 0.15 & 0.65 \\
\hline 36 & 33.026 & 9-aristolene & $\mathrm{C}_{15} \mathrm{H}_{24}$ & $6831-16-9$ & 0 & 0.68 \\
\hline 37 & 33.163 & agarospirol & $\mathrm{C}_{15} \mathrm{H}_{26} \mathrm{O}$ & $1460-73-7$ & 0 & 4.75 \\
\hline 38 & 33.36 & bulnesol & $\mathrm{C}_{15} \mathrm{H}_{26} \mathrm{O}$ & $22451-73-6$ & 0.29 & 0 \\
\hline 39 & 33.741 & alpha-bisabolol & $\mathrm{C}_{15} \mathrm{H}_{26} \mathrm{O}$ & $515-69-5$ & 0 & 1.94 \\
\hline
\end{tabular}

Notes: a The compound contents are high, both in NI and NF; CAS: Chemical Abstracts Service.

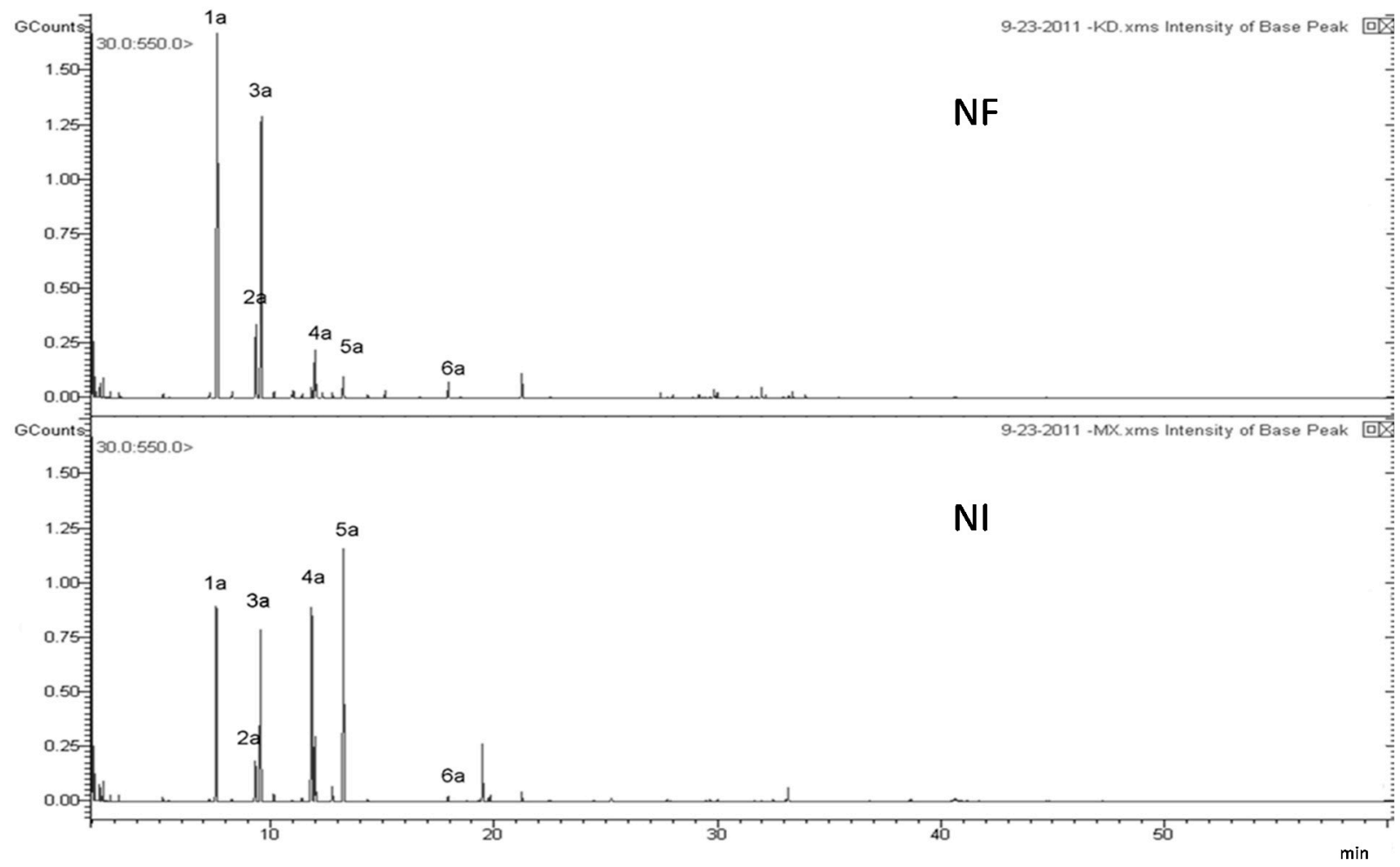

Figure 1. GC-MS chromatography profiling of Notopterygium franchetii (NF) and Notopterygium incisum (NI). 


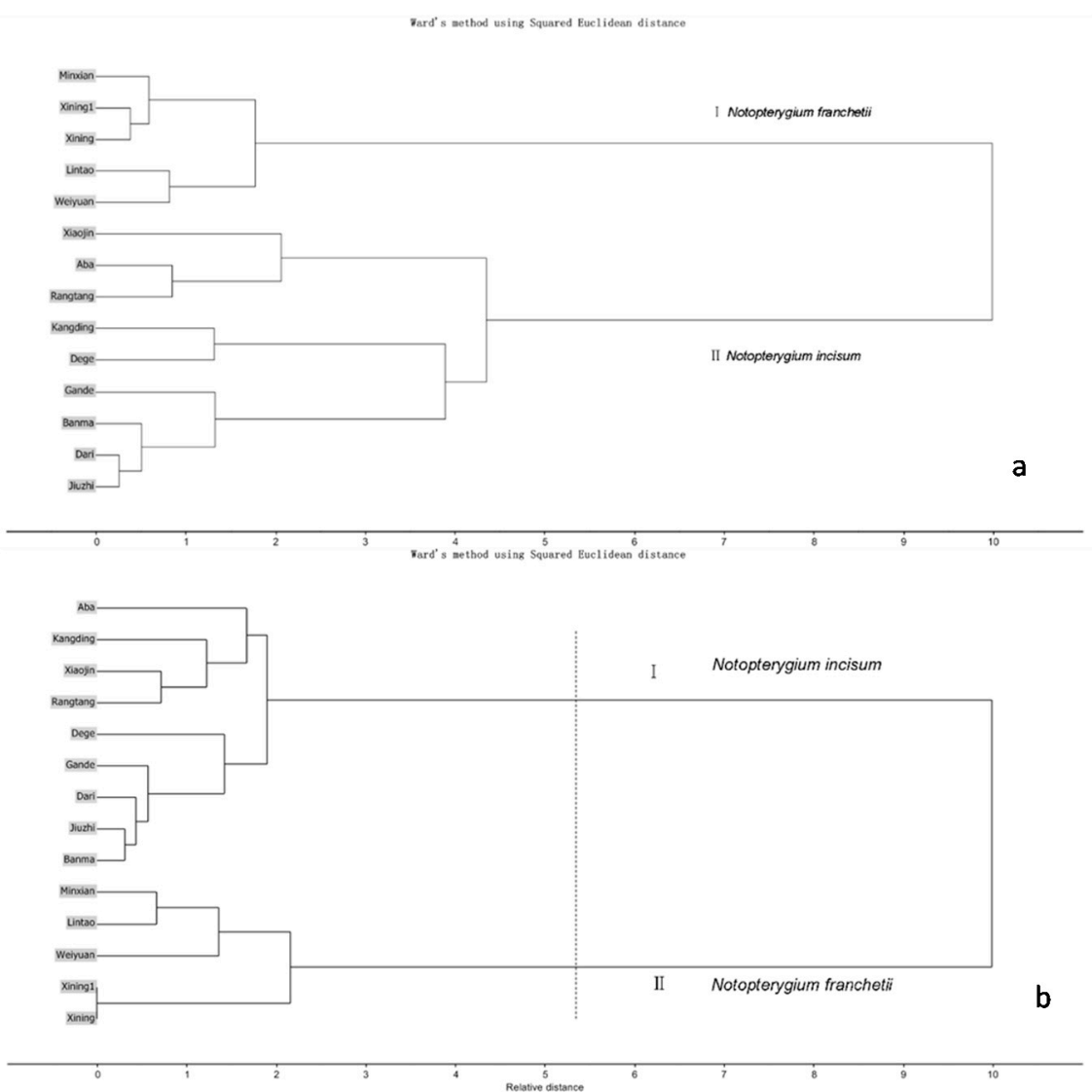

Figure 2. Hierarchical cluster analysis (HCA) results of 14 batches of Qianghuo samples based on GC-MS chromatograms (a) and HPLC fingerprints (b), respectively.

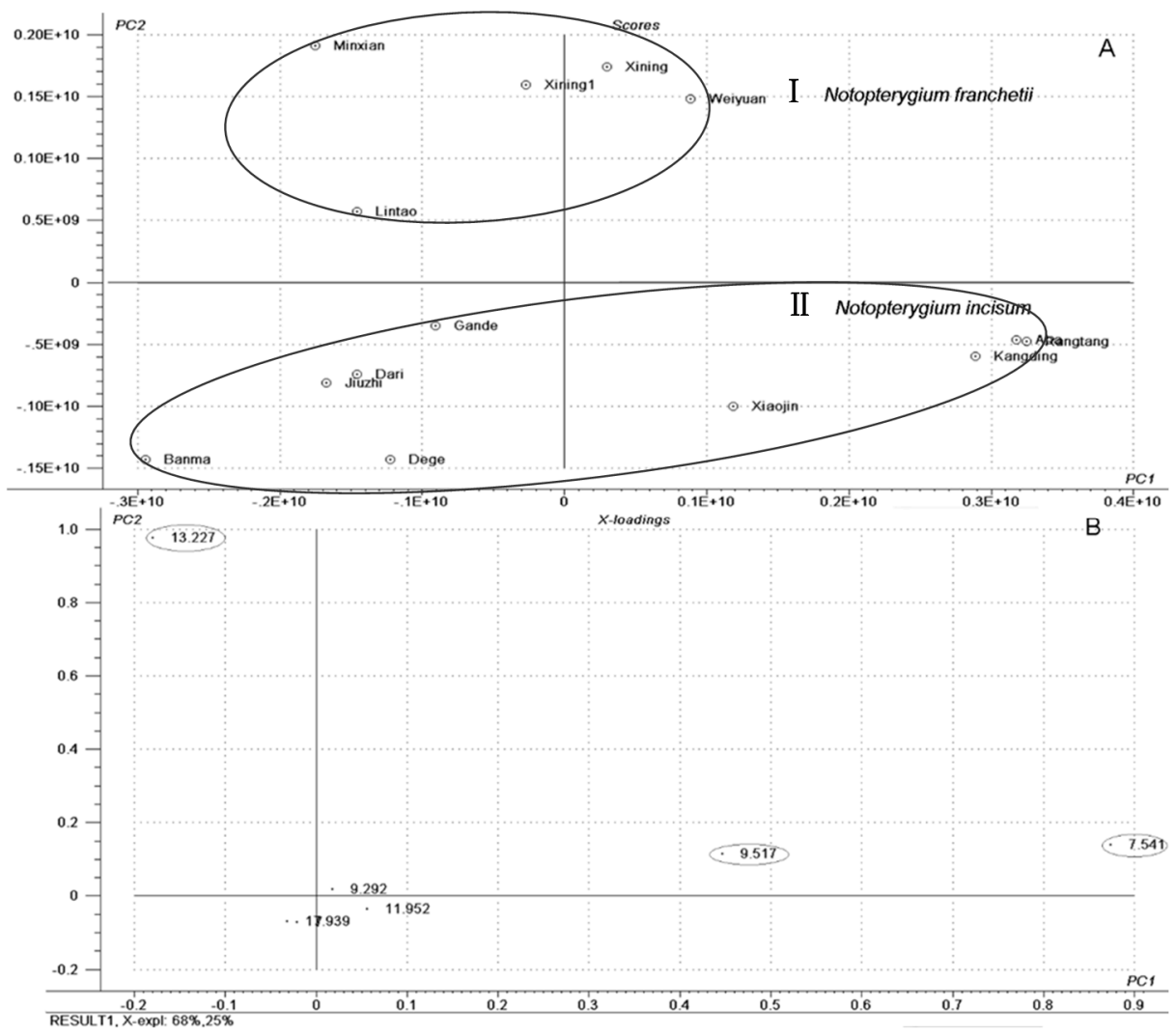

Figure 3. PCA scores plot (A) and loadings plot (B) for volatile oils in Qianghuo by GC-MS. 


\subsection{Analysis of Non-Volatile Compounds by HPLC}

The simultaneous determination of the four marker compounds in Qianghuo, including ferulic acid, bergapten, notopterol and isoimperatorin, was analyzed. The results of these two species from different locations are shown in Table 2. Notopterol and isoimperatorin are the chemical indicators in the Pharmacopeia of China (2010 edition) [1] of Qianghuo. The content of notopterol was higher in the NI samples than in NF samples; while the content of isoimperatorin was higher in NF than in NI samples. However, the differences of content in notopterol and isoimperatorin were not obvious in the same species. Therefore, the contents of these two compounds can be applied to distinguish the two species of Qianghuo. Bergapten presents pharmacological effects, including photosensitization, anticancer and inactivation of infectious pathogens and leukocytes in platelets and plasma [22], as a medicinal compound. It could not be detected in NI, which is from Dari county, Qinghai province. Therefore, bergapten was inappropriate as a marker compound in evaluating quality. Finally, the contents of bergapten and ferulic acid have no significant differences in NI and NF.

Table 2. Sample list: contents of the 4 compounds in Qianghuo (14 batches) and fingerprint similarities.

\begin{tabular}{|c|c|c|c|c|c|c|c|c|}
\hline \multirow{2}{*}{ No. } & \multirow{2}{*}{ Samples } & \multirow{2}{*}{ Location } & \multirow{2}{*}{ Species } & \multicolumn{4}{|c|}{ Content (mg/g) } & \multirow{2}{*}{ Similarities } \\
\hline & & & & (1) & (2) & (3) & $(4)$ & \\
\hline 1 & Xining $*$ & Xining city, Qinghai province & NF & 0.77 & 0.16 & 0.36 & 33.42 & 0.975 \\
\hline 2 & Xining * & Xining city, Qinghai province & NF & 0.77 & 0.16 & 0.35 & 33.41 & 0.972 \\
\hline 3 & Weiyuan & Weiyuan county, Gansu province & NF & 0.21 & 1.05 & 0.17 & 13.12 & 0.957 \\
\hline 4 & Minxian & Min county, Gansu province & NF & 1.38 & 1.12 & 0.58 & 20.07 & 0.994 \\
\hline 5 & Lintao & Lintao county, Gansu province & NF & 1.08 & 0.94 & 1.92 & 22.08 & 0.972 \\
\hline 6 & Rangtang & Rangtang county, Sichuan province & NI & 1.23 & 0.18 & 12.83 & 5.36 & 0.955 \\
\hline 7 & Xiaojin & Xiaojin county, Sichuan province & NI & 0.68 & 0.76 & 8.24 & 1.29 & 0.887 \\
\hline 8 & Aba & Aba county, Sichuan province & NI & 1.13 & 0.01 & 7.89 & 1.89 & 0.819 \\
\hline 9 & Jiuzhi & Jiuzhi county, Qinghai province & NI & 0.66 & 0.02 & 11.28 & 2.96 & 0.983 \\
\hline 10 & Gande & Gande county, Qinghai province & NI & 0.61 & 0.11 & 9.37 & 3.94 & 0.977 \\
\hline 11 & Dari & Dari county, Qinghai province & NI & 0.57 & ND & 8.14 & 3.03 & 0.988 \\
\hline 12 & Banma & Banma county, Qinghai province & NI & 0.56 & 0.07 & 10.40 & 3.20 & 0.981 \\
\hline 13 & Kangding & Kangding county, Sichuan province & NI & 1.97 & 0.28 & 22.79 & 4.72 & 0.970 \\
\hline 14 & Dege & Dege county, Sichuan province & NI & 0.91 & 0.11 & 13.88 & 4.21 & 0.933 \\
\hline
\end{tabular}

Notes: (1) ferulic acid; (2) bergapten; (3) notopterol; (4) isoimperatorin; ND: not detected. * S1: "tiaoqiang";

* S2: "datouqiang", * S1 and * S2 are two different kinds of Notopterygium franchetii.

\subsection{HPLC Fingerprint Analysis}

The chromatograms of the NF and NI samples (14 batches) are shown in Figure 4. Four main compounds were recognized by comparing the retention times and UV spectra with standards of ferulic acid, bergapten, notopterol and isoimperatorin. The profiles with reasonable heights and separation were assigned as "characteristic peaks" for the distinction of the two species. The correlation coefficient of similarity between each chromatographic profile of Qianghuo and the reference chromatogram, a representative standard fingerprint/chromatogram for a group of chromatograms, were calculated 
(Table 2), respectively. The correlation coefficients of the five batches of NF were higher than 0.95 , and the correlation coefficients of the nine batches of NI were higher than 0.80 . In Figure 4, the samples of NI and NF from different locations demonstrate certain differences. The differences among the chemical profiles of NI from different locations are bigger than of NF. This indicates that environmental factors may have more influence on the chemical composition of NI. These two species also show differences in the circled peak ( $t_{R} 26.77 \mathrm{~min}$ ) and Peak 3 ( $t_{R}$ 35.25). Besides, the chromatograms of the NI and NF samples can be divided into two groups by HCA (Figure 2). The HPLC fingerprint result of Qianghuo is significant for identifying the two species, because of their similar appearance, and provides scientific information about the species.

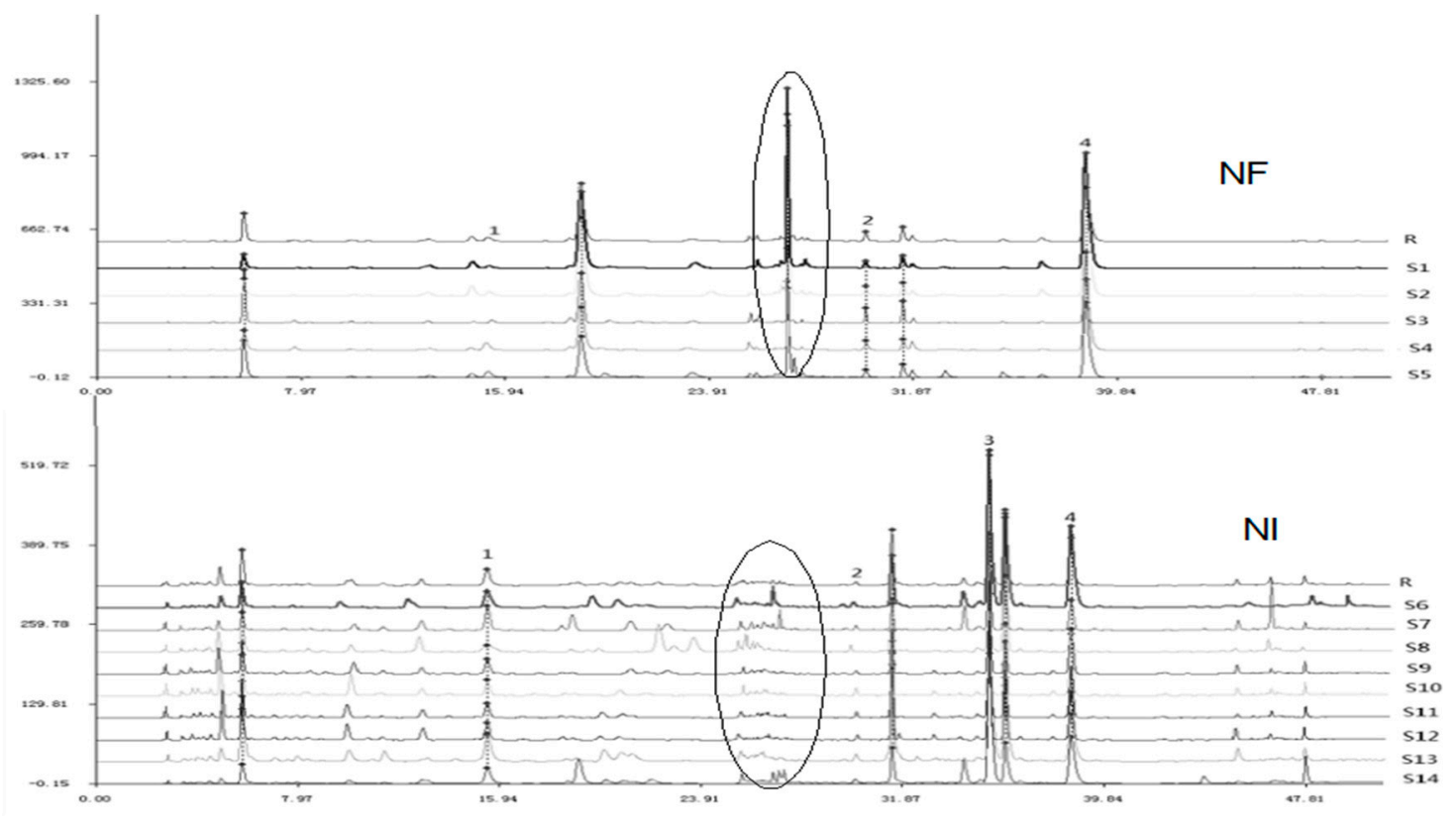

Figure 4. HPLC fingerprints of 14 batches of Qianghuo samples (R, reference chromatogram).

\section{Experimental Section}

\subsection{Plant Material}

In the present study, 14 batches of samples were collected from China in October, 2010 (Table 2). Among them, 5 batches were identified as NF, and 9 batches were identified as NI by Prof. Lin Yulin (Institute of Medicinal Plant Development, Chinese Academy of Medical Sciences, Beijing, China). The pictures of NI and NF are shown in Figure 5. Voucher specimens were deposited in the Herbarium of Institute of Medicinal Plant Development, Chinese Academy of Medical Sciences (Beijing, China).

\subsection{Chemicals and Reagents}

Ferulic and bergapten were purchased from the National Institute for Control of Pharmaceuticals and Biological Products (Beijing, China), and notopterol and isoimperatorin were purchased Tongtian Biological Co., Ltd. (Shanghai, China). Their structures are shown in Figure 6. The purity of the compounds was higher than 98\%, as determined by GC-MS or HPLC. Methanol (HPLC grade), acetic ether and acetonitrile were purchased from Fisher (Fisher Scientific, Fairlawn, NJ, USA); phosphoric 
acid (analytical grade) was purchased from Sigma (Sigma-Aldrich, St Louis, MO, USA). Deionized water was prepared by passing distilled water through a Milli-Q system (Millipore Corp., Bedford, MA, USA).

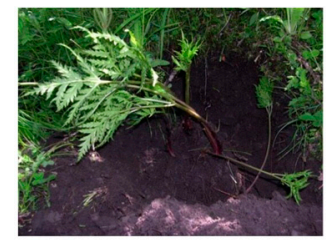

a

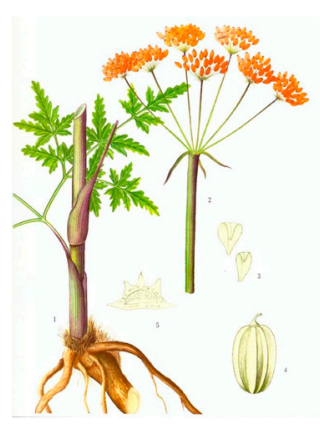

C

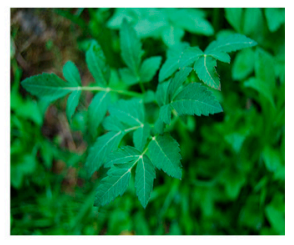

b

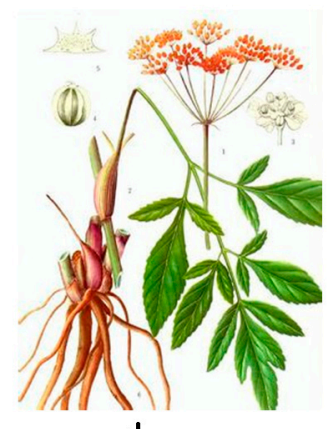

d

Figure 5. Pictures of NI (a,c) and NF (b,d).

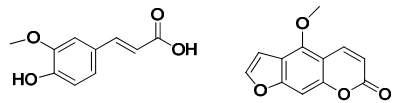

ferulic acid bergapten
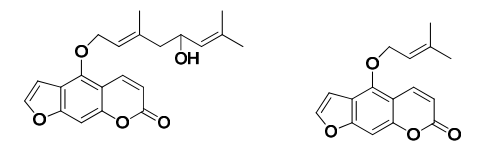

notopterol

isoimperatorin

Figure 6. Chemical structures of the standard compounds.

\subsection{Apparatus and Chromatographic Conditions}

GC-MS was performed with an Agilent 6890 gas chromatograph (Agilent Co., Palo Alto, CA, USA) coupled with a Varian 300 triple quadruple mass spectrometer (Varian Inc., Walnut Creek, CA, USA). The column was initiated at $50{ }^{\circ} \mathrm{C}$ at a rate of $2{ }^{\circ} \mathrm{C} / \mathrm{min}$ to $70{ }^{\circ} \mathrm{C}$, then to $118{ }^{\circ} \mathrm{C}$ at $5{ }^{\circ} \mathrm{C} / \mathrm{min}$. Later, the temperature was programmed from $118{ }^{\circ} \mathrm{C}$ to $128{ }^{\circ} \mathrm{C}$ at $2{ }^{\circ} \mathrm{C} / \mathrm{min}$ and kept for $2 \mathrm{~min}$; and finally, the temperature was increased to $240{ }^{\circ} \mathrm{C}$ at $8{ }^{\circ} \mathrm{C} / \mathrm{min}$ [15]. The temperature of the split injector was $250{ }^{\circ} \mathrm{C}$, and the split ratio was 15:1. High-purity helium (99.99\%) was used as the carrier gas at a flow rate of $30 \mathrm{~mL} / \mathrm{min}$. The spectrometer was operated in the electron-impact mode, and the ionization and photomultiplier voltage energy were $70 \mathrm{eV}$ and $1.25 \mathrm{kV}$, respectively. The ion source temperature was $230{ }^{\circ} \mathrm{C}$. The scan rate was $3.8 \mathrm{scan} / \mathrm{s}$, from 30 to $550 \mathrm{amu}$, with a solvent delay of $2 \mathrm{~min}$.

HPLC analysis was performed on a Waters 1525 system, including a 717 automatic sampler, a column oven, an on-line degasser, a binary gradient pump, a 2487 ultraviolet detector and the Waters chromatography working station Breeze 2 (Waters, Milford, MA, USA). A reverse-phase XBridge C18 column 
(250 $\mathrm{mm} \times 4.6 \mathrm{~mm} \times 5 \mu \mathrm{m}$, Waters, Milford, MA, USA) was used for separating, and the column temperature was kept constant at $35^{\circ} \mathrm{C}$. The mobile phase consisted of (A) acetonitrile and (B) water with $0.01 \%$ phosphoric acid $\left(\mathrm{H}_{3} \mathrm{PO}_{4}\right)$. The gradient program cwas as follows: $0-13 \mathrm{~min}(13 \%-17 \%, \mathrm{~B})$, 13-20 min (17\%, B), 20-22 min (17\%-44\%, B), 22-31 min (44\%-57\%, B), 31-38 min (57\%, B), $38-45 \mathrm{~min}(57 \%-100 \%, \mathrm{~B}), 45-50 \mathrm{~min}(100 \%, \mathrm{~B})[22,23]$. The flow rate was $1 \mathrm{~mL} / \mathrm{min}$, and the injection volume was $10 \mu \mathrm{L}$. The detection wavelength was set at $310 \mathrm{~nm}$.

\subsection{Sample Preparation}

For GC-MS analysis, the essential oils were obtained via water-steam hydrodistillation [24]. Ninety grams of the pulverized sample (through a 24-mesh sieve) were weighed accurately and then refluxed with water. The obtained volatile oil was dried using sodium sulfate anhydrous $\left(\mathrm{Na}_{2} \mathrm{SO}_{4}\right)$ and kept at $4{ }^{\circ} \mathrm{C}$, and the anhydrous volatile oils were diluted with acetic ether before injection. Then, $1 \mu \mathrm{L}$ of the diluted volatile oil was injected into the GC-MS system for each analysis.

For HPLC analysis, $200 \mathrm{mg}$ of the pulverized sample (through a 65-mesh sieve) were weighed accurately and macerated in $25 \mathrm{~mL}$ of methanol. The sample was then extracted for $30 \mathrm{~min}$ in an ultrasonic bath at $20^{\circ} \mathrm{C}$, and the loss of weight due to the evaporation of solvent was replenished with methanol. The supernatant was filtered through a $0.22-\mu \mathrm{m}$ membrane. Then, $10 \mu \mathrm{L}$ of the filtrate were injected into the HPLC system.

\subsection{Data Processing and Multivariate Analysis}

Comprehensive fingerprint profiles were performed by the "Similarity Evaluation System for Chromatographic Fingerprint of TCM" software (SESC-TCM, Version 2004 A, Chinese Pharmacopoeia Commission) $[25,26]$. The software can export the reference chromatogram based on correlation coefficients $\left(\mathrm{R}_{1}\right)$; the $\mathrm{R}_{1}$ was calculated with median or average data and was expressed as follows [27]:

$$
R_{1}=\frac{\sum_{i=1}^{n}\left(x_{i}-\bar{x}\right)\left(y_{i}-\bar{y}\right)}{\sqrt{\sum_{i=1}^{n}\left(x_{i}-\bar{x}\right)^{2} \sum_{i=1}^{n}\left(y_{i}-\bar{y}\right)^{2}}}(i=1,2,3, \ldots, n)
$$

The similarities of the samples are shown in Table 2. The HPLC fingerprint of samples were analyzed by HCA (Unscrambler ${ }^{\circledR}$ X, 10.1 trial version, CAMO Software AS, Oslo, Norway) based on Ward's method and the squared Euclidean distance. The identification of volatile oils in GC-MS was based on the NIST02 library, and relative height peaks of the identified compounds were analyzed by HCA (Table 1). The dataset of the volatile oil relative peak area was calculated via mean normalization.

\section{Conclusions}

In the present study, simple and accurate GC-MS and HPLC methods for the determination of 39 volatile and four non-volatile compounds were used to analyze NI and NF, two origins of Qianghuo. The GC-MS comparative analysis results of NI and NF showed that $1 R$-alpha-pinene, beta-pinene and 4-isopropyl-1-methyl-1,4-cyclohexadiene had a great contribution to the discrimination. Fourteen batches of Qianghuo from different locations were also assessed and distinguished by HPLC fingerprint analysis. With the combination of HPLC-HCA and GC/MS-HCA/PCA, the two species were found to 
differ significantly in both volatile and non-volatile compounds. Considering the differences in the chemical compositions, further investigation and comparison about the biological and pharmacological activities should be done to ensure the quality and efficacy of Qianghuo. Because NI grows at a higher altitude than NF, which means it is harder to cultivate, the price of NI is much higher than NF in the marketplace. Compared to the research conducted on NI, there exists little comparable research in the field of NI, and more work on NF is thus required in future studies.

\section{Acknowledgments}

The study was supported by grants from the National Natural Science Foundation of China (No. 81274013; No. 81130069; No. 81473315).

\section{Author Contributions}

Linfang Huang and Yaping Wang designed research; Yaping Wang performed research, analyzed the data and wrote the paper; Linfang Huang revised the manuscript. All authors read and approved the final manuscript.

\section{Conflicts of Interest}

The authors declare no conflict of interest.

\section{References}

1. Chinese Pharmacopoeia Commission. Pharmacopoeia of the People's Republic of China; People's Medical Publishing House: Beijing, China, 2010; Volume I, p. 170.

2. Okuyama, E.; Nishimura, S.; Ohmori, S.; Ozaki, Y.; Satake M.; Yamazaki, M. Analgesic component of Notopterygium incisum Ting. Chem. Pharm. Bull. 1992, 41, 926-929.

3. Guo, L.Q.; Taniguchi, M.; Chen, Q.Y.; Baba, K.; Yamazoe, Y. Inhibitory potential of herbal medicines on human cytochrome P450-mediated oxidation: Properties of umbelliferous or citrus crude drugs and their relative prescriptions. Jpn. J. Pharmacol. 2001, 85, 399-408.

4. Liu, X.; Jiang, S.Y.; Xu, K.J.; Sun, H.; Zhou, Y.; Xu, X.M.; Yi, J.H.; Gu, Y.C.; Ding, L.S. Quantitative analysis of chemical constituents in different commercial parts of Notopterygium incisum by HPLC-DAD-MS. J. Ethnopharmacol. 2009, 126, 474-479.

5. Ma, Z.Z.; Xu, W.; Chen, L.; Yuan, L.; Lee, D.Y.W. Novel coumarin glycoside and phenethyl vanillate from Notopterygium forbesii and their binding affinities for opioid and dopamine receptors. Bioorg. Med. Chem. 2008, 16, 3218-3223.

6. Xiao, Y.Q.; Baba, K.; Taniguchi, M.; Liu, X.H.; Sun, Y.F.; Kozawa, M. Coumapins from Notopterygium incisum Ting. Acta Pharmaceutica Sinica 1995, 4, 274-279.

7. You, M.; Xiong, J.; Zhao, Y.; Cao, L.; Wu, S.B.; Xia, G.; Hu, J.F. Glycosides from the methanol extract of Notopterygium incisum. Planta Med. 2011, 77, 1939-1943.

8. Guo, F.Q.; Liang, Y.Z.; Xu, C.J.; Huang, L.F. Determination of the volatile chemical constituents of Notoptergium incium by gas chromatography-mass spectrometry and iterative or non-iterative chemometrics resolution methods. J. Chromatogr. A 2003, 1016, 99-110. 
9. García-Argáez, A.N.; Ramírez Apan, T.O.; Parra Delgado, H.; Velázquez, G.; Martínez-Vázquez, M. Anti-inflammatory activity of coumarins from Decatropis bicolor on TPA ear mice model. Planta Med. 2000, 66, 279-281.

10. Keri, R.S.; Hosamani, K.M.; Shingalapur, R.V.; Hugar, M.H. Analgesic, anti-pyretic and DNA cleavage studies of novel pyrimidine derivatives of coumarin moiety. Eur. J. Med. Chem. 2010, 45, 2597-2605.

11. Wu, S.B.; Pang, F; Wen, Y.; Zhang, H.F.; Zhao, Z; Hu, J.F. Antiproliferative and apoptotic activities of linear furocoumarins from Notopterygium incisum on cancer cell lines. Planta Med. 2010, 76, $82-85$.

12. Xu, H.B.; Sun, X.B.; Zhao, Q.C. Pharmacological research on the volatile oil of Notopterygium incisum. Chin. Tradit. Herb. Drugs 1991, 22, 28-31.

13. Huang, L.F.; Li, W.T.; Wang, Z.; Fu, J.; Chen, S.L. Correlative study between chemical constituents and ecological factors of Notopterygii Rhizoma Et Radix of endangered plateau plant. Acta Ecol. Sin. 2013, 33, 7667-7678.

14. Tan, Y.; Zhang, H.; Sun, Y. Determination the content of nodakenin from Notopterygium incisum by TLC densitometry. Chin. J. Chin. Mater. Med. 1996, 21, 486-487.

15. Qiu, Y.Q.; Lu, X.; Pang, T.; Zhu, S.K.; Kong, H.W.; Xu, G.W. Study of traditional Chinese medicine volatile oils from different geographical origins by comprehensive two-dimensional gas chromatography-time-of-flight mass spectrometry (GC× GC-TOFMS) in combination with multivariate analysis. J. Pharm. Biomed. Anal. 2007, 43, 1721-1727.

16. Zhang, S.J.; Li, C.L.; Zhou, G.Y.; Che, G.D.; You, J.M.; Suo, Y.R. Determination of the carbohydrates from Notopterygium forbesii Boiss by HPLC with fluorescence detection. Carbohydr. Polym. 2013, 97, 794-799.

17. Zhang, S.; You, J.M.; Zhou, G.Y.; Li, C.L.; Suo, Y.R. Analysis of free fatty acids in Notopterygium forbesii Boiss by a novel HPLC method with fluorescence detection. Talanta 2012, 98, 95-100.

18. Xu, K.; Jiang, S.Y.; Zhou, Y.; Zhang, Y.X.; Xia, B.; Xu, X.M.; Zhou, Y.; Li, Y.F.; Wang, M.K.; Ding, L.S. Discrimination of the seeds of Notopterygium incisum and Notopterygium franchetii by validated HPLC-DAD-ESI-MS method and principal component analysis. J. Pharmaceut. Biomed. 2011, 56, 1089-1093.

19. Crowell, P.L.; Chang, R.R.; Ren, Z.B.; Elson, C.E.; Gould, M.N. Selective inhibition of isoprenylation of $21-26-\mathrm{kDa}$ proteins by the anticarcinogen d-limonene and its metabolites. J. Biol. Chem. 1991, 266, 17679-17685.

20. Chaudhary, S.C.; Siddiqui, M.S.; Athar, M.; Alam, M.S. D-Limonene modulates inflammation, oxidative stress and Ras-ERK pathway to inhibit murine skin tumorigenesis. Hum. Exp. Toxicol. 2012, 31, 798-811.

21. Gan, H.L.; Che Man, Y.B.; Tan, C.P.; NorAini, I.; Nazimah, S.A.H. Characterisation of vegetable oils by surface acoustic wave sensing electronic nose. Food Chem. 2005, 89, 507-518.

22. Yang, W.; Feng, C.; Kong, D.; Shi, X.; Cui, Y.; Liu, M.; Wang, Q.; Wang, Y.L.; Zhang L.T. Simultaneous and sensitive determination of xanthotoxin, psoralen, isoimpinellin and bergapten in rat plasma by liquid chromatography-electrospray ionization mass spectrometry. J. Chromatogr. B 2010, $878,575-582$. 
23. Qian, G.S.; Wang, Q.; Jiang, Z.H.; Zhao, Z.Z.; Qin, Y.; Kelvin, S.Y.L. Quality assessment of Rhizoma et Radix Notopterygii by HPTLC and HPLC fingerprinting and HPLC quantitative analysis. J. Pharmaceut. Biomed. 2007, 44, 812-817.

24. Zhong, G. Studies on optimum extraction technology for volatile oil in Notopterygium by orthogonal test. Chin. J. Mod. Drug Appl. 2008, 11, 26-27.

25. Lin, P.; Wang, Y.Z.; Zhu, H.B.; Chen, Q.M. Fingerprint profile of active components for Artemisia selengensis Turcz by HPLC-PAD combined with chemometrics. Food Chem. 2011, 125, 1064-1071.

26. Wei, H.; Sun, L.N.; Tai, Z.G.; Gao, S.H.; Xu, W.; Chen, W.S. A simple and sensitive HPLC method for the simultaneous determination of eight bioactive components and fingerprint analysis of Schisandra sphenanthera. Anal. Chim. Acta 2010, 662, 97-104.

27. Lv, S.D.; Wu, Y.S.; Zhou, J.S.; Lian, M.; Li, C.W.; Xu, Y.Q.; Liu, C.W.; Wang, C.; Meng, Q.X. The study of fingerprint characteristics of Dayi Pu-Erh tea using a fully automatic HS-SPME/GC-MS and combined chemometrics method. PLoS One 2014, 12, e116428.

Sample Availability: Samples of the compounds not are available from the authors.

(C) 2015 by the authors; licensee MDPI, Basel, Switzerland. This article is an open access article distributed under the terms and conditions of the Creative Commons Attribution license (http://creativecommons.org/licenses/by/4.0/). 